\title{
FROM BEHAVIORAL DESIGN TO REVERENCE FOR LIFE: CARE POLICIES FOR THE DIGITAL ENVIRONMENT
}

\section{Konstantin A. Ocheretyany}

St. Petersburg State University. Saint Petersburg, Russia. Email: kocheretetyany[at]gmail.com

\begin{abstract}
The article raises the problem of the ecology of a human being in a digital reality, namely, the issue of caring for a resource accessible to any person living in new conditions. The aim of the study is to substantiate the need for a transition from the behavioral design as well as the corresponding ethological paradigm to the existential design, involving a more responsible and careful approach to ecology and ethics in human capital management in the context of cognitive capitalism and digitalization of life. In the modern world it is often the question of productivity growth and technological advancement. Meanwhile, the question of human capacities and incapacities (mental, physical, behavioral) does not arise. Taking into account the absence of a caring attitude towards human capacities, this resource will never go turn into human capital. The research demonstrates that the design of digital media allows the use of the available human resources more properly if technical requirements of speed, quantity, simplicity are changed in compliance with existential requirements (changes in the subject of herself/himself, not in the objects of her/his activities) increasing his/her role, ethical meaning, feeling of presence in the event, tracking the results of actions and a deeper awareness of the results. The article is aimed at media philosophers, anthropologists and theorists of digital culture.
\end{abstract}

\section{Keywords}

behavioral design; reverence for life; existential design; control policies; care policies; digital reality; cultural logic of interfaces; mediaphilosophy; cognitive capitalism

This work is licensed under a $\underline{\text { Creative Commons «Attribution» 4.0 International License }}$ 


\title{
ОТ БИХЕВИОРИАЛЬНОГО ДИЗАЙНА К БЛАГОГОВЕНИЮ ПЕРЕД ЖИЗНЬЮ: ПОЛИТИКИ ЗАБОТЫ ДЛЯ ЦИФРОВОЙ СРЕДЫ
}

\author{
Очеретяный Константин Алексеевич \\ Санкт-Петербургский государственный университет. Санкт-Петербург, Россия. \\ Email: kocheretetyany[at]gmail.com
}

\begin{abstract}
Аннотация
В работе поднимается проблема экологии человека в цифровой реальности: заботы о доступном человеку ресурсе в новых технических условиях жизни. Цель исследования - обосновать необходимость перехода от бихевиориального дизайна (и соответствующей этологической парадигмы) в пользу экзистенциального дизайна - более ответственного и внимательного отношения к экологии и этики работы с человеческим капиталом в ситуации когнитивного капитализма и цифровизации жизни. В современном мире, речь часто идет только о росте производительности и о совершенстве технического обеспечения, забывают о возможностях человека и его невозможностях: ментальных, физических, поведенческих. В ходе исследования было показано, что дизайн цифровых сред позволит более комплексно, бережно и целесообразно использовать имеющийся в распоряжение у человека ресурс (время, внимание, психофизиологические и культурно-поведенческие особенности) если откажется от технических требований скорости, количества, простоты (т.е. того что может сделать субъект) в пользу экзистенциальных изменений в самом субъекте, увеличение его роли, значения, этической силы, чувства присутствия, возможности отслеживать результаты своих действий, более глубокого осознания их результатов. Статья рассчитана на медиафилософов, антропологов и теоретиков цифровой культуры.
\end{abstract}

\section{Ключевые слова}

бихевиориальный дизайн; благоговение перед жизнью; экзистенциальный дизайн; политики контроля; политики заботы; цифровая реальность; культурная логика интерфейсов; медиафилософия; когнитивный капитализм

Это произведение доступно по лицензии Creative Commons «Attribution» («Атрибуция») 4.0 Bceмирная 


\section{ЗАБОТА - ПОТЕРЯННАЯ ЭНЕРГИЯ?}

Что происходит в нас, когда включаются экраны наших устройств? Поставленный вопрос - выражает современные тенденции теории медиа, когнитивных исследований, социологии и психологии, а также восстанавливает древний смысл философии как практики включенных наблюдений над изменениями способа существования. Имена ее семиотически избыточны и семантически неэквивалентны:

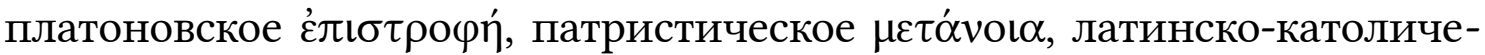
ское conversio, контрреформаторское-модерновое meditatio, но в том числе и близкие к нам die Kritik и die Dialektik. Какое бы имя мы не выбрали для практики включенных наблюдений, предварительный ответ на вопрос легко наметить: когда включаются экраны наших устройств в нас выключается внимание - мы вступаем в те способы существования в которых еще не умеем жить и которые даже не замечаем. Британский фантаст Дж. Баллард описывает моральную и эпистемологическую слепоту ученых в романе «Затонувший мир» (1962), где экологический кошмар стал реальностью - глобальное потепление вызывает таяние ледников, увеличение водной массы, возвращение флоры и фауны из доисторического прошлого Земли в день сегодняшний. В ситуации экстремальных изменений, ученые действуют согласно усвоенным эпистемическим добродетелям: отмечают факты «внешней» экологии, удивляются возвращению к жизни древних растений и животных, фиксируют координаты наблюдений, составляют тщательные описания, каталогизируют их - но все это бессмысленно, ведь под воздействием тепла и вместе с увеличением водной территории изменяется «внутренняя» экология - обратную эволюцию испытывают сами люди, становясь существами с иным чувствованием, иным мышлением, иным образом мира. Их тело изменяется быстрее чем успевает приспособиться к изменениям их мысль. Увеличивающийся разрыв обессмысливает их наблюдения, стратегии, решения, любую модель поведения. Как и персонажи Балларда мы сегодня оказываемся в той ситуации, когда внешние изменения, их многочисленность и сложность - отвлекают от изменений, имеющих место в нас самих.

С перемещением в цифрровые среды жизни меняемся мы сами, но мы еще недостаточно внимательны к этим изменениям. Тело со времен Дарвина мыслилось более приспособленным к прошлому, чем к настоящему, поскольку несло в себе память о биологической адаптации и случившихся катастрофах. Технологии со времен Маркса мыслились скорее, как конструкторы социаль- 
ного будущего, а не инструменты приручения настоящего, адаптивные решения уступали место стохастическим сценариям. Но сегодня наше тело изменяется быстрее, чем наши ментальные привычки и навыки, ведь наше тело сегодня - это наши технологии, а они не столько укоренены в прошлом, сколько открыты будущему. А потому нам необходимо в новых условиях актуализировать ту практику внимания, которая под различными именами: лробохй, cogito, die Genealogie, Die Hermeneutik - являлась одной из ключевых добродетелей, культивируемых в целом ряде философских дискурсов, ставших определяющими для типа мышления, дальними наследниками которого мы являемся. Все перечисленные выше имена философской практики включенного экзистенциального внимания $\kappa$ изменениям способам существования - с древности имели корнем заботу, $\dot{\varepsilon} \pi \mu \varepsilon \dot{\lambda} \varepsilon\llcorner\alpha$. При увеличении забот наблюдается хронический дефицит заботы. Забота - оказывает потерянной энергией, которая при невнимании в ней работает против нас. Забыв про нее, мы просто не сможем использовать ее в освоении нового цифрового мира, а значит наша задача - вернуть ее.

В чем же состоит дефицит заботы? Проведем параллель. В космологии скрытая масса (или потерянная масса) - проблема, указывающая на противоречие между наблюдаемым поведением видимых объектов и расчётных законов, которые не были бы полны учитывая лишь эти объекты. Большая часть Вселенной - это X, черная материя и черная энергия, о которых ничего неизвестно. Наблюдаемые объекты ничего не объясняют, ненаблюдаемые отношения объясняют все, но о них ничего неизвестно. Если космологи, а затем по их образцу социологи (Латур, 2006, стр. 199-223), искали потерянную массу для того, чтобы объяснить видимые явления, то философы медиа ищут потерянную (скрытую) энергию, для того чтобы объяснить видимую логику действия, модели поведения, а также возможный спектр их модификаций (вплоть для искаженных и превращенных форм). Характерно, что вопрос потерянной массы и потерянной энергии в XX веке приобрел аксиологическую и этическую размерность. В. Флюссер заметил, что в мире, где человечеству грозит захлебнуться собственной жаждой, целый ряд исследовательских направлений: археология, этимология, психоанализ, экология и т.д. сосредоточены вокруг проблемы вышедшего из употребления - неактуализируемого в утилитарных координатах разума (2016, с. 118). Действительно, в современном мире природа больше не рассматриваться как ресурс. «Биологический жизненный процесс, активный обмен веществ человека с природой, как он осуществляется в труде, смог достичь такой 
чудовищной интенсивности, что его растущая результативность в конечном счете угрожает самостоятельности самого мира и продуктивной способности, которой он обязан своим возникновением» (Арендт, 2017, сс. 394-395). Там, где искали мощь - контроль природных сил, организация, повышения темпов производства, усиление используемых энергоресурсов - была обнаружена слабость, угроза всеобего истощения. Но в том, что касается природы внутренней - т.е. заботы о нашем психофизиологическом ресурсе в цифровой среде ситуация не столь однозначна. Фактически в деле выживания в новой среде мы признаем и принимаем технические решения и правила, адаптируясь к машинному ритму, но оказываемся морально и эпистемологически слепы к энергии, направленной на адаптацию.

Парадокс всемогущества Бога вставал в раннехристианской рефлексии, ведь обладая неограниченным могуществом Бог мог мыслиться и как существо, бесконечно множащее собственные невозможности, силой, создающий сущности, с которыми невозможно справиться. В постсекулярную эпоху мы приходим к тем же противоречиям: не умножает ли наше могущество наши немощи? Августин сумел разрешить парадокс не менее парадоксальной формулировкой: «Потому-то нечто и невозможно для Него, что Он всемогущ» (Августин, 1998, с. 209). Не стоит ли применить этот парадокс сегодня в анализе отношения человека к технологиям? Мы должны обратить внимание не на наши силы и возможности, а на наше бессилие, невозможности и упущения - иначе наша природа даст сдачи.

\section{ИНТЕРФЕЙС КАК БИОПОЛИТИЧЕСКАЯ ТЕХНОЛОГИЯ}

Современные технологии и их развитие неотделимы от политических, экономических и социокультурных тенденций: все они воплотились в интерфейсе как привилегированной форме доступа к жизненному миру. Но если интерфейс дает привилегированный доступ к жизненному миру, то это означает, что интерфейс влияет и на то, как человек ведет диалог с миром, с жизнью и какие вопросы ей адресует. Следовательно, правомерен вопрос: насколько продуктивен этот диалог и на каком языке он ведется?

Согласно Агамбену, решающий политический конффликт в нашей культуре - конфликт между животностью и человечностью, а потому политика, как и искусство управления и контроля, в т. ч. лежащее в основе наших технологий - есть изначально биополитика. Его теорию подтверждает экономическая антропология еще во второй половине XX века, показавшая, что прежняя экономическая аналитика 
была формально-, а не субстанциально-ориентирована (Поланьи, 2014, c. 147), т.е. переносила модели производства, обмена, потребления товаров, характерные для рыночных условий и общественных отношений, сложившихся в Западной Европе на определенном временном отрезке на весь мир, не учитывая игры, праздники, ритуальное взаимное одаривание, ритуальный круговой обмен, т.е. существенные качественные отличия в понимании ценного и престижного, в т. ч. от экономики до сих пор ускользали техники тела. В этом ключе Ж.-П. Вернан совместно с религиоведом М. Детьеном описали греческую категорию «metis» («хитрость», «уловку») как особое «телесное» знание, установив параллель между целым рядом институционных «надстроек» и общественных взаимодействий и соответствующих им «настроек» культурного тела, показав искусство политики как ансамбль поведенческих и телесных техник: от ритуальных празднеств и состязаний до публичных выступлений (Détienne \& Vernant, 1974). В 1957 году историк Э. Канторович перевел проблему телесности в область того, что он сам охарактеризовал «политической теологией» показав, что юристы, историки и теологи Средневековья и раннего Нового времени фактически удвоили короля (по аналогии с богочеловеческим телом Христа) понимая его как смертного индивида и как сакральную институцию; тело короля с одной стороны продукт природы и с другой стороны - ритуалов и церемоний (Канторович, 2013). В 1649 г., когда Палата общин казнила природное тело короля Карла I Стюарта, она же унаследовала его политическое тело: в этом смысле теология не перестала существовать, а скорее стала материальной силой, превратилась в технологию управления и контроля для реальной политики над телами и душами. Агамбен, опираясь на указанную традицию, полагает, что политика понятая теологически - есть специфическая форма «бездеятельности», иными словами, действие, превращающее все остальные действия в отсутствие деятельности (Агамбен, 2019, с. 12).

Если отнестись всерьез к приведенным здесь тезисам: 1) решающий политический конфликт в нашей культуре проходит между «животностью» и «человечностью» человека; 2) теология не исчезает, а становится материальной силой - технологией; 3) политика понятая теологически - есть действие, превращающее все виды деятельности в ничто, в бездеятельность - то напрашивается вывод о том, что технология становится теологической силой, которая обессмысливает действия человека, т.е. все менее делает человека субъектом собственного действия. 
Археолог Эндрю Шеррат предположил, что революция в человеческой истории (или даже начало истории) лежит в переоценке ценностей в отношении к животным - в определенный момент их стали использовать не как материал, но как энергию - то, что работает на человека в долгосрочной перспективе, дает человеку «вторичный продукт» - тягловую силу, тепло, удобрения и т.д. (Манко, 2019, стр. 138). Человек стал не просто убивать животных, но держать их про запас. В определенном смысле революция вторичных продуктов оказалась перманентной и постоянно интенсифицировалась: в случае с животными стали использовать не только живые тела, но и мертвые, переработанные в недрах земли (нефть); в случае с людьми стали использовать не только их тела, но и души, не только их знания (сознательное действие), но и незнания (бессознательное поведение, желание). Древняя философская проблема - «душа», эмансипированная от теологии в конце XVIII века попадает в XIX веке (т. е. при указанном превращении теологии в технологию управления и политику контроля) под влияние физиологии, а потому ключом к ее пониманию становятся экспериментальные техники, эмпиризм и позитивизм, даже мышление в XX веке начинает рассматриваться в бихевиориальном ключе как сумма операциональных навыков, а потому изменение поведенческих стратегий, через опосредование операций новыми техническими условиями рассматривается как ключ к новому мышлению. Субъект мышления не в «Я» или в теле, он в условиях поведенческих практик. Симптоматичным примером (и ключевым для понимания цифровой революции) служит то, как Ванивер Буш - ученый, работающий в системе обороны США отразил дух времени в своей статье «Как мы можем мыслить?», опубликованной в 1945 году в журнале Atlantic Monthly (Bush, 1991, pp. 85-112). Буш фактически представил современный дизайн интерфейсов, описав воображаемую машину, похожую на стол с прозрачными экранами и работающую с текстами и изображениями. Все ключевые метафоры на месте: рабочий стол, файлы и папки, иконки приложений и изображений. За ставшим уже энциклопедическим фактом («долгоиграющей» модели Буша, до сих пор обнаруживаемой и в наших устройствах), часто сложно заметить, чем обусловлена эффективность этой модели - ее бихевиориальную ориентацию. Дизайн наших интерфейсов до сих пор бихевиориальный дизайн: его суть, как и в опытах Скиннера - в вознаграждении за поведение, а это значит, что он по необходимости аттрактивен и аддиктивен. Он провоцирует жажду, не ведя к ее утолению. В таком случае компьютеры скорее не технологии взаимодействия, а технологии влияния, 
производства аффекта и управления эмоциями: они изначально на уровне дизайна дают нечто сделать для того, чтобы спровоцировать и подчинить. Если изобретение Раймонда Луллия было машиной, на которой человек задавал вопросы Богу, то изобретение Буша, стало машиной, на которой новая реальность, получившая статус божественной, предписывала человеку императивы. Б. Дж. Фогг из Стэнфордского университета обосновал исследовательское направление «каптологию» (акроним от computers as persuasive technologies, компьютеры как технологии влияния) и создал целую лабораторию, изучающую как веб-сайты, программные приложения и мобильные устройства можно использовать для изменения отношения и поведения людей (Fogg, 2002). Вопрос о новых возможностях таким образом превращается в вопрос о новых формах влияния, где животное начало в человеке сведено к моделям поведения и к вознаграждению за выбранную модель: компьютеры не наделяют человека расширенным разумом, а третируют его как животное. Диалог с животным началом в человеке ведется не на основание предпочтений и ограничений (или заботы), а на основании интенсификации контроля и результата (или эксплуатации). Если тело - это набор поведенческих программ, а их техническая модификация - это возможные способы взаимодействия и мышления, то все что ускользает от технической модификации поведенческих программ не является ни мышлением, ни действием, ни даже восприятием «...Если бы я захотел точно выразить перцептивный опыт, мне следовало бы сказать, что некто во мне воспринимает, но не я воспринимаю» (Мерло-Понти, 1999 сс. 276-277). Техника при таком подходе не позволяет предпринять действия, а убеждает действующего в том, что он всегда делает недостаточно, а все сделанное им мгновенно превращаются в ничто.

Если в дизайне цифровых сред благоговение перед жизнью как учет различных способов отношения к спектру модусов телесного существования в касании и затронутости не придет на смену бихевиориальной эксплуатации, то любые действия, совершенные в интерфейсах наших устройств, грозят превратиться в специфическое отсутствие деятельности, хроническую неудовлетворенность, невозможность в полноценном смысле быть. Например, Клаус Шваб прогнозирует (Шваб, 2018), что четверка ключевых технологий современности: блокчейн, 3D-печать, нейросети, Big Data - создадут ситуацию, где машины будут принимать решения, которые человек не сможет понять, а возможно и принять, несмотря на их формальную правильность. Юваль Ной Харрари убедительно показывает (Харрари, 2020), что поскольку организмы - это алгоритмы, а сила homo sapiens 
в создании интерсубъективных конструктов, способных упорядочивать, репрезентировать и модифицировать данные опыта, то в ситуации, где большие данные и соответствующие технологии, становятся парадигмой человек утрачивает лидирующую роль. Более того согласно его прогнозам, технологические разработки напрямую угрожают способности человека придавать жизни смысл. Символично, что предшественником Шваба и Харарри был Беньямин сначала показавший, что: протестантизм, восстав против различных форм иерархий опустошил мир, уничтожив миф и оставив только ритуал (Беньямин, 2002, с. 139), а затем объяснивший, что капитализм стал не просто продолжением протестанской этики, а - новой религией основанной на фетишиских ритуалах (Беньямин, 2012, сс. 99-107), где чем больше мы делаем, тем дальше мы от результата. Цифровая реальность - реальность когнитивного капитализма и бихевиориальной этики в такой постбеньяминовской интерпретации становится новой формой религиозного фетишизма, где ритуал (потенциально любое действие) работает не на создание смысла, а на его изгнание: получая более мощные инструменты человек как бы лишается целей (и даже инструкций) их использования. На уровне экологии медиа проблема потерянной энергии - превращающения заботы в контроль, действующего в подопытного сохраняется. Л. Манович определяет цифровую среду как продолжение бюрократии иными средствами (Манович, 2017 , сс. 70) - иначе говоря, избыточность правил, следуя которым действие противоречит себе или даже парализует себя. В. Флюссер задавался вопросом об этике промышленного дизайна - о том, к какому способу существования подталкивают нас среды обитания и к каким действиям (и катастрофам) используемые инструменты (Флюссер, 2016, сс. 75-79). Ф. Киттлер отмечал связь оптических условий видения в современных цифровых средах со взглядом снайпера, с оптикой военного видения вещей - где открытость, потенциально означает и большую уязвимость, а совершенство - хрупкость. Баллистические, криминалистические и криптографические решения в области оптики, продолжают жить в наших цифровых медиа и обживать наши тела - а мы словно еще сильнее влюбляемся в их власть. «Мы все еще находимся на Второй Мировой войне» (Киттлер, 2009, сс. 246). Все, что мы делаем в цифре, таким образом цифрой же может оборачиваться против нас, если мы не учитываем возможности цифры изменять и превращать отношения. Тогда видимые элементы становятся совершенно необъяснимы вне принятия в учет возможных структур. Бихевиориальные технологии перечисляемые Фоггом: сужение взгляда и упрощение действия 
(Simplification), руководство (Guidance), кастомизация (Customization), вмешательство (Just-in-time intervention), принуждения к самоконтролю (Self-monitoring), коррекция поведения через отслеживание действия (Surveillance), формирования привычек, через создание условий для действия (Conditioning) - во многом полезные в медицинском мониторинге - в других случаях становятся избыточно дисциплинарными, вступая в противоречие с такими формами человеческого капитала как комплексное решение проблем, критическое мышление, креативность, умение управлять людьми, взаимодействие с людьми, эмоциональный интеллект, умение анализировать и принимать решения, навык ведения переговоров, гибкость мышления (Fogg, 2002).

\section{ИНТЕРФЕЙС КАК БИОСЕМИОТИЧЕСКАЯ ПРОГРАММА}

Интерфейс - как перформативная визуальная грамматика цифрового мира был надстроен над бихевиористским истолкованием природы - но это не значит, что он ей исчерпывается. Напротив, он изменяет наши способы жить - демонстрируя, как и в чем мы до сих пор ограничены, используя наивную прикладную интерпретацию бихевиористкой программы. Обращение к природе, к животному - традиционная реакция на кризис культуры. Сегодня - это реакция на обращение происходящее в существе самого человека или с человеком как существом: реакция на кризис бихевиориального дизайна оболочек наших устройств, в которые мы все больше переводим нашу жизнь. Человек до сих пор не смог осмыслить животное начало в себе и выстроить диалог с ним иначе как на языке алгоритмов, и оно мстит ему - закрываясь от него им же созданными технологиями, отделяя его от самого себя. Бихевиориальный дизайн интерфейсов - создание условий возможности, подталкивание к их осуществлению действия, вознаграждение за выбранную модель поведения и повторение вплоть до истощения, а не до результата - свидетельство глубинного сбоя в том, что Дж. Агамбен называет антропологической машиной как совокупности концептуальных схем, сил и аппаратов управления, которая была способом для человека приостановить собственную животность - создать чрезвычайное положение, свободную и пустую зону. Антропологическая машина служила мотором историзации человека, но вместо свободы, чрезвычайное положение создало отделенную от себя самой и исключенную жизнь «голую жизнь» (Агамбен, 2012, сс. 50). Единственным отношением становится - предельно интенсивное использование животного/тела как ресурса, оборачивающегося принуждением и насилием. 
Именно эти моменты и подлежат деконструкции. Следует поставить вопрос: что если дело не в том, будто человек все еще слишком животное для того, чтобы войти в новый мир алгоритмов, а напротив, - в том, что он недостаточно животное, поскольку продолжает мыслить живое как набор алгоритмов и поведенчиских программ нацеленных на эффективность? Тогда «провал биополитики» контроля живого в новых интерфейсах (имагинативной и перформативной грамматики цифрового мира), оказывается требованием новых концептуальных схем, сил и аппаратов - возникновением новых форм жизни при изменении знаков (Барт, 1994, сс. 278).

Обратимся к биосемиотике как одному из исследовательских направлений способным объяснить возникновения новых форм жизни и новых способов жить (в т.ч. числе среди технических образов и знаков). С точки зрения биосемиотики организм имеет тенденцию к превращению внешнего информационного взаимодействия во внутренний бессознательный процесс (Ямпольский, 2019, сс. 32).

\begin{abstract}
«Главное для живого существа - это селекция того, на что оно должно реагировать и что игнорировать. Чтобы осуществить эту селекцию, любое существо должно быть способно “читать", отбирать информацию, что-то извлекать из "информационного шума”. <... > По мере передачи информации что-то изменяется в сети, а затем происходит стабилизация системы. Информация в биологических системах в конце концов превращается в энергию. Мы видим еду, реагируем на нее как на сигнал, съедаем и в конце получаем энергию. Картинка, на которую реагирует животное (ягоды, плод, убитое существо), в какой-то момент все равно ведет к энергии» (Ямпольский, 2019, сс. 17-18).
\end{abstract}

Итак, основная забота живого с биосемиотической точки зрения селекция: она начинается из взаимодействия между животными видами, а затем - продолжается на уровне взаимодействия с изображениями. Из совокупности взаимодействия с животными по аналогии с интерсубъективностью и интеробъективностью ее можно назвать интеранимальностью - создалась особая экосреда и имунносреда, обеспечивающую коллективный иммунитет. Психологическими и социальными двойниками этой эко- и иммуносреды (и следствием интеранимальности) были ментальные техники работы с собственными эмоциями - знаки, впечатанные в тело, коллективный иммунитет в области эмосферы (отсрочка гнева, желания и т.д.). Так, например, в эссе «О добывании огня» Фрейд мифопоэтически показывает изменение в психофизиологии человека: поддержание огня в общине возможно только при отказе от аутоэротического удовлетворения, получаемого человеком при гашении пламени 
струей мочи (Фрейд, 1995, сс. 339-342). Животные в их буйстве (не зря мифологическое воображение соотносит их со стихиями) - то же пламя, а потому от человека требуется соответствующее внимание как к их возможной агрессии, так и к своим удовольствиям. Если он хочет получать от них нечто - он должен дать им больше. Отсроченное потребление - результат сосуществовании с животными в том же смысле, что и отсроченный аффект. Скорее животные приручили человека, чем он животных. В этой связи Агамбен обращается к Хайдеггеру, напоминая, что «животность» человека может быть понята не только как то, что необходимо взять под контроль посредством техники, но и как то, что фундаментально сопротивляется господству, что мыслится в человеке как чистая оставленность (Агамбен, 2012, с. 96).

«Dasein - это попросту животное, которое научилось скучать, которое пробуждается из собственно оцепенения в собственное оцепенение» (Агамбен, 2012, с. 85).

Скучающее животное, животное, смеющее ждать - все эти характеристики называют бихевиориальный недуг человека, отсрочку действия. Но если бихевиориальный дизайн интерфейсов как продолжение биополитики средствами цифровых технологий есть действительность, обращающая все формы действия в ничто, то такие «ничтожные» действия как скука, оставленность, оцепенение - свойственные человеку могут, напротив, оказаться действиями, обращенными на себя, значимыми сами по себе. Если животные «приручили» человека дав реализовать его «непродуктивное» искусство ждать, то какие возможности открывает коммуникативная и семиотическая среда интерфейсов для реализиции потенциала человека? Какие его «недуги» еще не получили статус добродетелей только потому, что мы по инерции следуем поверхностно понятым бихевиоральным решениям? Возможно, что задача интерфейсов не вести к умножению результата и закрепления поведения, но, наоборот, работу с осознанием и принятием собственных несовершенств? Возможно в новых условиях они могут дать больше? Антропологическая машина как модель власти и контроля, обрекла нас на мышление о жизни в терминах алгоритмов, но сейчас она требует новой биосемиотической программы: иного взгляда на природу - вместе с введением новых знаков и перформативных практик. Homo Sapiens, даже этимологически не только человек разумный, но человек «чувствительный», чуткий - он укоренен не в продукте и контроле (праксисе), но в заботе и даре (поэзисе). Даже интерсубъективные конструкты, способные 
моделировать данные опыта - это не столько результат расчета и прогноза (праксис), сколько поэзис и эстезис, игра и праздность, изначальное внимание к границам, чуткость: любой образ, модель, схема есть проявление этой чуткости, которая глубинно уходить к священному переживание границы между животным и человеком. Граница эта больше становится ясна не из логики контроля и управления, а из глубинного эстезиса соприкосновения, сопереживания, в расширенном смысле, определенном А. Швейцером как «благоговение перед жизнью», восприятию животного начал в себе как жизни, находящейся в бедствии и одновременно священной. А. Пшера анализируя новые цифровые возможности в экологической перспективе предлагает модель «интернета-животных», которые благодаря коммуникативным сетям и новым связям между человеком и животным могли бы технологически реализовать эсхатологический идеал А. Швейцера и М. Бубера: обращения объективистских отношений «Я»-«Оно» к сочувствующим «Я»-«Ты». «Единственное, что имеет смысл - это сопереживание» (Пшера, 2017, с. 151). Но можно пойти и дальше, прогнозируя, что внимание к новым технологиям и новым связям изменят отношения между человеком и животным в самом человеке: бихевиориальный дизайн, основанный на позитивистском, эмпирическом истолковании жизни и практической эксплуатации животного начала в человеке как ресурса, будет уравновешен (если не заменен в новой биосемиотической ситуации) экзистенциальным дизайном, имеющим в основе благоговения перед жизнью во всей ее полноте, в т. ч. ко всех ее несовершенствам. Цифровой век - век тотальной коммуникации, а значит век растущей неопределенности: мы все чаще имеем дело с редкими и уникальными событиями, которые можно прогнозировать только всерьез относясь к несовершенствам человека. В противном случае даже экономический рост, который традиционно соотносится с усилением в обществе роли новых технологий остановится стандартизацией форм коммуникации.

\section{СМЕНА ПАРАДИГМЫ: ОТ КОНТРОЛЯ К ЗАБОТЕ}

Если благоговение перед жизнью - возможная альтернатива бихевиориальному дизайну, то в чем она могла бы состоять? Прежде всего необходимо избавиться от распространенной идеологической предпосылки - аргумента «от реальности». Легко принять на веру призывы обратиться к самим вещам, т.е. увидеть в дизайне цифровых приложений деятельность конкретных компаний, коллективов, авторов, в сетевой коммуникации - «реальных» адресатов и отправителей, а в требованиях к пользователю - конкретные юридиче- 
ские и экономические ситуации, с которыми вынуждено считаться цифровое человечество. Тем не менее такая установка - глубоко идеологична, т. к. «конкретные» люди и ситуации, в не меньшей степени результат цифррового взаимодействия, чем акторы и условия. Поэтому в данном случае не так важно анализировать кто и зачем действует, как понять принципы и возможные результаты действия. Именно эти принципы и возможные результаты - есть сама реальность. Следовательно техники заботы о себе в цифровой реальности, по необходимости, не столько психологические, сколько экзистенциальные установки - способы быть, которые следует учесть в дизайне цифровых интерфейсов.

Благоговение перед жизнью - не стоп-кран для действующих стратегий, а комплексный взгляд, осознание того, что животную природу человека до сих пор использовали не целесообразно. Замыкание жизни в бихевиористкой матрице привело к тому же, что и предметное отношение к природе, выраженное в росте производительности и потребления - к истощению. Наступление на природу в технологиях, должно смениться ее открытием: иначе цифровая реальность - всего лишь продолжение техно-бюро-милито-кратии, а не новый уровень экзистенциального онтопоэзиса. До сих пор «забота» в отношении к технологиям мыслилась как легкость и доступность, как скорость и производительность, но это все еще технические, a не экзистенциальные добродетели - которые могут, наоборот, привести к катастрофам, т.к. предполагают неисчерпаемость возможностей, или садизм псевдоморальных требований. Цифровой дизайн, напротив, мог бы учесть феномен слабой силы, т. е. начаться с отношения к животному началу, или к самой жизни как к тому, что находится в бедствии, крайне ограничено и ценно, и, тем самым, были бы актуализированы новые стороны человеческого бытования в цифре. Но каковы же экзистенциальные установки, которые вводя чрезвычайное положение - т. е. фиксируя ограниченность и ценность человеческого капитала - могли бы стать основаниями для цифрового дизайна в модусе благоговения перед жизнью?

\section{О, ДИВНЫЙ БЕСКОНТАКТНЫЙ МИР}

Поскольку цифровой интерфейс - наша биосемиотическая программа и биополитическая парадигма, то изменяются наши способы взаимодействия с миром, а это означает, что изменяемся мы сами, причем прежде изменения интеллекта происходит адаптация к новым условиям, развитие нового инстинкта. Меняется наша телесная схема, т.е. способы устроенности в собственном теле и 
возможные модусы его использования. «Самый простейший визуальный аппарат - это рука. Уже на самых ранних стадиях, когда ее применение было совершенно недифференцированным, создавались ментальные образы, сделанные рукой, main images, как говорит французский исследователь Лева. На более высоких стадиях развития рука через прикосновения, повторяя контуры, нащупывая форму и схватывая чужие тела, создает первые искусственные и художественные формы, которые выделяются из мира практических действий и маркируют независимый от него порядок» (Гебауэр, 2013, с. 101). От Аристотеля и вплоть до Гуссерля (Husserl, 1952, S. 143-161), проблема касания проблема способов данности мира, функционального отношения и различных конфигураций, складывающихся между жестом, взглядом, переживанием ${ }^{1}$. Для Хайдеггера, Деррида и Нанси, касание - это и проблема затронутости: всякое касание затрагивает и нас, а затронутость определяет возможное касание (Landes, 2007, pp. 80-92). Но цифровой мир - мир бесконтактный. Это не значит, что мы больше не взаимодействуем ни с кем, это значит, что наше взаимодействие опосредовано технологией, т.е. уже не технологии продолжение и развитие руки, но рука - продолжение и развитие технологий. Нащупывание схватывание, прикосновение, повторение контуров - не отношение руки к вещам, а скорее вещей к нам: сканер

1 Касание и сопутствующую ему затронутость - важно понимать в контексте высказывания Хайдеггера: Der Mensch «hat» nicht Haende, sondern die Hand hat das Wesen des Menschen inne «Не человек «имеет» руки, а именно рука владеет существом человека» (Хайдеггер, 2006, с. 96) и сопутствующего комментария Деррида: «Во-первых, on the one hand [с одной стороны], как обычно говорят по-английски, все выглядит (насколько мне известно) так, как будто единственное предложение, в котором Хайдеггер говорит о руках человека во множественном числе, касается как раз момента молитвы или, во всяком случае, жеста,в котором складываются (sich falten) обе руки, чтобы в Einfalt [односложности] объединиться. Хайдеггером постоянно привилегируется Versammlung [собранность]. Во-вторых, on the other hand [с другой стороны] никоим образом ничего не говорится о ласке или о вожделении. Делается ли любовь, занимается ли человек любовью рукой или руками? И как обстоит дело в этом отношении с сексуальным различием? Можно вообразить себе протест Хайдеггера: этот вопрос носит выводной характерто, что вы называете вожделением или любовью, имеет своей предпосылкой появление (avènement) руки из слова, и с того времени, как я указал на руку, которая дает, подается, заверяет (verspricht), отдается, предоставляет, вручает и обязывает в уговоре и клятве, вы располагаете всем, что вам нужно, чтобы осмыслить то, что они вульгарно называют занятием любовью, лаской или вообще вожделением.- Может быть, но почему нельзя об этом сказать?» (Деррида, 2006, с. 298). Если Хайдеггер делает акцент на собранности руки (в смысле молитвы, жеста прошения и прощения, единения и внимания, экзистенциальной расположенности, заботы). Деррида замечает, что открытость руки, приходящая на место собранности есть противоречие - сужение горизонта ее интенционального конституирования - от заботы к вожделению. Тот же ход мысли необходимо применить и в оценивании интерфейсов как биосемиотической парадигмы для выживания в цифрровом мире: их открытость - чаще всего не экзистенциальная расположенность, а предопределенность к действию, через мотивацию и поощрение - т.е. касание и вживание оказываются обратнопропорциональны на практике и прямопропорциональны в теории. В идеале собранность должна показывать возможные модели открытости, а открытость - и необходимые принципы собранности. 
отпечатка пальца, лица, распознавание голоса: биополитические, криминалистические, криптографические решения. Наше первое отношение к технике сегодня - поверхностно тактильное. Мы чаще не давим на кнопки и не жмем на рычаги - мы даже не касаемся, а скорее отдаемся касанию/сканированию. Легкость прикосновения обеспечивает скорость и невесомость, проникновение заменено скольжением по поверхности. Мы более не связываем технику с отсрочкой аффекта и началом мысли, напротив, на собственном опыте познаем, что мысль есть страсть. Скольжение по поверхности - это прежде невозможность зацепиться и охватить - поэтому техника как сканер должна нас «объять». Следствия очевидны: касаются друг друга уже не тела и технологии, но технически-усиленные мысли, страсти, чувства, фантазии - их любовное трение есть игра, ставка в которой тело, не в смысле субстанциальной воплощенности, а в смысле укорененности в пространстве, времени, причинно-следственной связи. Сегодня мы оказываемся в странной ситуации - касание нас не затрагивает, а затронутость - нас не касается: т.е мы собственным касанием будто бы вбираем мир, а на деле исторгаемся из собственного тела. Американский журналист Мэтью Пауэрс, погибший при расследовании в Уганде, за полгода до своей смерти в 2013 году показал социологам, как в отсутствии физической угрозы для жизни эмоционально выгорают операторы беспилотных дронов, испытывая стрессы более мучительные, чем те, кто непосредственного и телесно вовлечен в боевой контакт (Вахштайн, 2017, стр. 2): эмоции освобожденные от тела стремительно интенсифицируются и напротив, повышенная интенсификация эмоций означает актуальность, а вместе с ней вещность, материальность, фактичность. Новые технологии следует развивать не по логике больших возможностей, а по логике большей затронутости и ответственности. Касание без затронутости - превращается в скольжение или болезненную реакцию, т.е. в невозможность удержаться, воздержаться и поддержать, в выключенность из мира. Д. Бутройд вслед за Левинасом и Деррида подчеркивает нарциссизм дизайна, существующих технических интерфейсов: они обеспечивают легкость и доступность, но не экзистенциальную открытость, ставя на карту механизмы конституирования этической предметности - т. е. встречу с Другим (Boothroyd, 2009, pp. 330-345). В ситуации биополитической эксплуатации тела средствами бихевиориального дизайна, когда мысль становиться страстью, а страсть - мыслю, страстям не хватает именно «тягости», т.е. чувства веса, лишившись, которого они неконтролируемо разрастаются. Бесконтакность оборачивается замыканием на фантазме, а рост эмоций - скорее аутоэротическим 
фактором, чем основанием к действию. Альтернативу видят в возвращение затронутости, т.е. ограничение нейрофизиологичеческого истолкования «кожи», и возвращение ей экзистенциальной размерности (Elo, 2012 pp. 1-12). Через обратную связь, отдачу, возвращается не только ответ на действие, но и чувство того, что всякий эффект имеет вес. Следует отметить, что на уровне практики данные решения уже давно начали опробоваться в игровой среде (Ленкевич, 2019 , стр. 20-33) - авангарде цифровой реальности, а новейшие технические решения уже запатентованы компанией Sony под говорящим именем контроллера PlayStation 5 - DualSense.

\section{SLOW LIFE MATTERS}

Поскольку цифровые интерфейсы уже - по крайней мере в игровой индустрии - смещаются от количества функциональных возможностей и способов означивания к акцентуации проблемы присутствия, стоит ожидать, что со временем и в других областях цифрового мира чуткость и внимание к переживаемому должна прийти на смену скорости, количеству и точности отклика. В данном случае важно отметить, что проблема скорости вместе с оцифровыванием мира становящаяся сквозной для всех сфер жизни - уже побудила тревогу и подготовила условия для противодействия. Достаточно напомнить o slow life - «субкультуру, основанную на ценности замедления ритма жизни. Со временем движение распространилось на различные сферы и области, возникли идеологии, акторы и адепты «медленных путешествий», «медленного искусства», «медленного телевидения», «медленного производства», «медленных денег», «медленной медицины», «медленного образования» и т. д. Последователи slow полагают, что их реализация возможна благодаря активному применению принципов, заимствованных из различных дисциплин научного знания. Во всем используется квалитативный подход (делать все, как можно лучше, а не как можно быстрее) и индивидуалистическая философия уникальности каждого субъекта. Движение ориентируется на созерцательный и вдумчивый образ жизни, считает непродуктивным взятие на себя лишних обязательств и многозадачность, но при этом отрицает какой-либо аскетизм. Адепты slow life действуют на различных социальных площадках: блоги, сообщества, например дизайнеров (slow design), рестораны slow food, журналы slow living и пр. [...] Инструментарий slow living заимствован из таких направлений современных кросскультурных исследований, как: интегральная теория (Integral Theory) и целостный подход (A Holistic Approach) в саморазвитии; бихевиоральная экономика (поведенческая эконо- 
мика) - наука о том, как мы делаем потребительский выбор; теория спиральной динамики развития человека (Spiral Dynamics); исследования, касающиеся нашего отношения к времени (Time Studies); теория «вдумчивого» моделирования и анализа принятия решений и стратегического планирования в бизнесе и различных организациях (Appreciative Inquiry); несколько теорий новейшей экзистенциальной и межличностной психологии» (Николаева, 2016, стр. 25-26).

Современный цифровой мир определен не столько свободой действия, сколько необходимостью действия: с помощью новых средств, оболочек, плагинов, приложений, гаджетов и т.д. ты можешь делать больше и лучше, а, следовательно, вынужден делать больше и лучше. Мы до сих пор видим достоинство в том, чтобы делать дальше и лучше, и этому научили нас технологии, традиционно опознаваемые как внеморальные средства. Латентным образом они вели свою морализаторскую работу - демонстрируя нам, что если ты не успеваешь, значит не понимаешь, а значит - бесполезен. Сейчас речь идет напротив о том, чтобы морализовать технологии - т. е. показать, что граница, остановка, предел, начало не стыда, а рефлексии. Интерактивный дизайн интерфейсов, ориентирован больше на реакцию, но введение элементов темпорального и рефлексивного проектирования (Hallnaes, Redstroem, 2001, pp. 201-212), могло бы способствовать тому, что эффективность обнаруживалась не в реакции, а в отсрочке внимании, вживании и размышлении.

Culturally Embedded Computing Group - группа исследователи из Нью-Йорка, сосредоточенная на культурно-ориентированных технологиях, проанализировала колоссальный массив литературы, проектов технологий и исследовательских тенденций и показала (Sengers, Boehner, David, Kaye, 2005, pp. 49-58), что такой переход от рефлекса к рефлексии, от агрессии действия к понимающему сопереживанию на уровне дизайна цифровых сред возможен при учете следующих моментов: 1) совместное проектирование (participatory design) - т.е. более тесное и открытое взаимодействие, не только предоставлению пользователю нового, но и привлечение его внимания к тем навыкам, которые уже у него есть, их новое открыти; 2) чувствительность к ценностям (value-sensitive design) - т.е. принятие в учет, того, обстоятельства, что каждое действие это еще и манифестация ценностей, которые разделяет и которым сочувствует пользователь; 3) критически-ориентированные установки (critical design) - т. е. заимствованные у арт-критики методы выведение пользователя по ту сторону потребительской культуры, через деконструкцию того, что они знают и ценят, а также через провокацию воображения, 4) людоло- 
гические функции ludic design - т.е. указание альтернативных возможностей и предоставление большей свободы действия; 5) практика критического использования техники (critical technical practice) - т. e. внимание к тому какие метафоры и метонимии в интерфейсах предопределяют способы понимания и переживания техническиобусловленного опыта; тактика рефлексивного действие (reflection-inaction) дизайн должен избегать овеществления опыта и вместо этого поддерживать диалогический характер, то есть делать акцент не на ситуации, а на обстоятельствах, которые к ней привели. Ключевая тенденция состоит в том, чтобы возвращать пользователя к себе, тем самым возвращая ему из эксплуатационного - экзистенциальный статус, а вместе с ним - ценности и смыслы. Замедление, здесь основание для обращения внимания на себя, на причины и следствия собственных действий, на условия формирования событий и ситуаций в которых развертывается экзистенция.

\section{КОГДА МЕНЬШЕ, ЗНАЧИТ БОЛЬШЕ}

Х. Арендт, исследуя основания современности, замечает, что человек в своей активности - сократив расстояния и наладив техническую коммуникацию - стал больше обитателем Земли, чем своего места и времени на ней. Мы отчуждены не от самих себя, как полагал Маркс, а - от мира (Арендт, 2017, стр. 313-323). Мир оказывается потерянным измерением и эта утрата компенсируется экспансией себя, избыточностью себя, граничащей с фантазмом. Современный мир избыточной активности - экспансия фантазматического «Я». Поскольку все действия направлены на его подкрепление мы все менее способны к поступку, т.е. к открытию этического измерения стояния перед Другим. Эффективность, следовательно понимается как манифестация Я, а не принятие Другого - чем больше мы делаем, тем больше мы замыкаем себя в координатах здравого смысла (или в интерпретации Арендт, в cogito без dubito, в сознании, лишенном сомнения, для которого каждое последующее действие подтверждает правоту предыдущего). Следовательно, многочисленные экзистенциальные основания действия и поступка в схемах трудовой (сегодня главным образом - цифровой) действительности оказывают дискредитированы как неэффективные: скука, боль, одиночество, страх - должны быть блокированы. Втянутые в координаты общества принудительного счастья, мы приговорены к искаженным формам vita activa, деятельной жизни, где деятельность - скорее иной род пассивности. Вынужденные встраиваться в технические способы взаимодействия и приспосабливаясь к их требованиям, мы просто не замечаем 
утрату множества необходимых моментов этического поступка. Так, например, мы лишены скуки - ее приостанавливают и подавляют новостные ленты, события, мероприятия, дедлайны; лишены боли - не только фармакологически, новыми болеутоляющими, но и тем, что невозможно переживать боль одному - социальные сети всегда дадут сочувствующих и позволят пережить работу траура коллективно; лишены одиночества - за нами присматривает наш друг смартфон, мы гладим его, говорим с ним, спим с ним, а просыпаясь - первым делом берем его в руки. Наверно, и самый распространенный диалог в современном мире начинается с: «Привет, Сири!», а заканчивается на: «Ок, Гугл!».

Фактически мы лишены того, что со времен античных и иудеохристианских истоков европейской культуры было началом бытия и мышления, мы отказываемся от нашего биологического основания в той же мере, что и от нашего культурно-исторического наследия, а значит - они начинают работать против нас. Фармакология современных интерфейсов состоит в том, чтобы не дать почувствовать нам ни боли, ни одиночества, ни тоски, ни страха и возможно вместе с этими потерями, мы теряем те связи с миром, которые удерживают нас во времени, пространстве, в собственном теле. Отсюда значимая задача - принять всерьез контрэффективность, т.е. учитывать не только скорость, количество операций, многозадачность, адаптивность (мимикрия, напомним, - влечение к смерти, поскольку она растворяет в среде), но и другие тенденции, часто рассматриваемые как негативные, но необходимые для остановки, внимания, оценки, понимания, для укоренения во времени, пространстве, причинноследственных связях с целью более полного их переживания, прочувствования, продумывания. Интерфейсы цифровых устройств работают

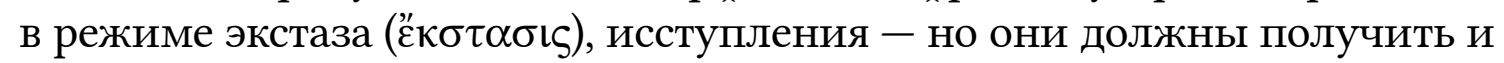
режим эпохэ (غ́лохи́) воздержания.

Прежде всего не стоит бояться действия без содержания, нуль необходим для выстраивания координат. Герой Уилла Смита в комедии Hitch (2005) объясняет принципы коммуникации: «60 процентов в общении между людьми составляет невербальная часть. Язык тела. И 30 процентов - звучание голоса. Таким образом, 90 процентов того, что Вы выражаете, не связано с речью». Нулевая степень коммуникации или пустой контакт - необходим для запуска коммуникации. Хотя о нем самом ничего сказать нельзя, он делает возможной не только сообщение, но и сообщество, т.е. не только передачу данных, но и экзистенциальную включенность. Р. Якобсон говорил о таком пустом контакте как о фатическом (лат. Fatuus - 
глупость) акте речевой коммуникации, при котором речевые высказывания, не неся смысловой нагрузки направлены на установление контакта с собеседником (Якобсон, 1975, стр. 201). Все это говорит о том, что моменты, которые традиционно рассматриваются как неутилитарные, а потому избыточные и неэффективные - необходимы. Они дают силу и значение контакту, т.е. потенциально - ответственность за него, наделяют его этическим измерением.

Кроме того, любой момент неудовлетворённости - самоценен. Удача, психологически мотивирует к действию воспитывая автоматизм повторения, неудача - к осознанию причин. Нас выбрасывает к самим себе и иногда это повод впервые установить с собой диалог. Добавим: приостановка счастья компенсируется более комплексным взглядом на жизнь. Мир возвращается к нам и там, где мы испытываем неудачу, потому что, теперь мы чувствуем его присутствие, а не только свое. «Мы ничего не имеем против счастья, речь идет не о самом этом хрупком чувстве, а о его превращении в какой-то коллективный наркотик, который все обязаны принимать в том или ином виде: химическом, духовном, психологическом, информационном, религиозном. <...> А молодому Мирабо я бы ответил так: «Я слишком люблю жизнь, чтобы желать одного лишь счастья» (Брюкнер, 2011, стр. 14).

Если принять всерьез цитированное выше положение Хайдеггера о том, что человек - скучающее животное, то скука необходима. Когда не совершается ничего значительного вовне, нечто меняется в нас самих - мы обращаемся к себе и учимся быть с собой. Во многом это необходимо для начала бытия с другими, ведь терпеливость ожидания воспитывает терпимость по отношению к другим. Эффективность современных технических средств может обернуться катастрофической нетерпимостью, если с помощью этих средств человек не научится управлять собой, а будет видеть цель лишь в побуждении других, скуку воспринимать как отсутствие действия, а отсутствие реакции на действия как неприятие и обиду. Принятие скуки в учет цифрового дизайна - возможный ответ на угрозу разрастания ressentiment.

Нерешительность, также необходимо перестать рассматривать как проявление слабости. Бихивеориальный дизайн цифровых оболочек поощряет одни типы поведения и оставляет без внимания другие, но часто мы не замечаем, что наша решимость - скорее подталкивание, а техническую обеспеченность подталкивания, принимаем за собственную решительность. Мы настойчиво действуем не в своих интересах. Напротив, нерешительность как dubito - является осно- 
вание cogito (мы вспоминали это в связи с X. Арендт), ограничение себя - дает место для события. Цифровой мир не стал пространством диалога, напротив, породил внутренние требования и критерии к оформлению высказывания, которые сказались и на содержании мысли. Нерешительность в данном случае не слабость, а эмпирический скептицизм - возможная ценностная установка, отказывающаяся от вознаграждения за поведение, в пользу анализа альтернативных моделей. Установку на «сделать любыми средствами» следует заменить на установку «оценивания достойности целей»: механицизм цифрового поведения, на телеологию цифрового поступка. Если все действия, не отданные интерфейсу - обращаются в отсутствие деятельности, то отсутствие деятельности мы должны, напротив оценить как начало мышления.

В этом смысле цифровое взаимодействие должно определяться не только открытостью к возможным действиям, но и осознанностью того, что происходит с нами и в нас. «Эпохэ», приходящее на смену «экстазу» в дизайне интерфейсов (и в целом - в практике цифррового действия), - это внимание к причинам и следствиям, к способу конституирования события и условиям его возможности. Важно помнить, что всякое действие - не только изменяет нечто вне нас, но и изменяет нечто в нас, т.е. определено сопротивлением или даже болью. Принять боль всерьез означает перейти от эстетической стадии к этически прочувствованному переживанию себя, своей мотивации и ценностной ориентации. Цифровая реальность может выводить из мира, но она при правильном ее использовании может и столкнуть человека впервые с собой. Важно помнить, что капиталистическая мораль - вещественная мораль, исторически продиктованная отношением к имуществу и имущественным правом. Цифровая реальность превращает вещь в программу, меняет понимание вещи- а вместе с ней и формы морали, показывая, что вещи все менее принадлежат нам, как и время, как и пространство - все это скорее арендуется, берется взаймы. Но вместе с этими изменениями технологии цифровой реальности открывают нам истину нашего существования, показывая, что мы никогда не являлись теми, за кого часто себя принимали, что дело человека заботиться о себе, а не о вещах, в т. ч. не о том, что может быть овеществлено. Бездействие в цифре важнее, чем активность, т.к. оно открывает возможность иных моделей деятельности, иных типов действительности, этически (а не только эстетически) расширенного мира. Техника вынуждает умножать активность, но она может и пригвождать к бездеятельности (поскольку все делает сама). Отсюда ее эсхатологическая задача - принудить к бездеятельности. 
Не к нулевой степени действия, а действия - которое как нуль является началом координат, т.е. показывает ряд возможностей и ставит вопрос об альтернативе. Ведь принимая на себя из сферы поведения и мышления только то, что может быть переведено на язык практических операций, техника осуществляет специфическое эпохэ, показывая, что существо человека не сводится к алгоритмам (раз уж они могут быть заменены машинами и программами), и пробуждая онтологическое беспокойство, необходимость искать иные экзистенциальные проекты. Предоставляя возможности для бездействия она учит нас новой боли - боли быть человеком и не скрываться от нее в ложно понятой активности с которой неплохо справляются и программы.

\section{ВЫВОДЫ}

«В миланской Амвросианской библиотеке хранится еврейская Библия XIII века с ценнейшими миниатюрами. <...> Миниатюрист представил увенчанные главы праведников не с человеческими, а с несомненно звериными лицами. <..> Почему же предстватели человеческого совершенства изображены со звериными головами? $<\ldots>$ Ученые до сих пор не нашли удовлетворительного ответа. <...> Между тем, не является невозможным то, что миниатюрист Амвросианской рукописи, наделяя остаток Израиля головами зверей, имел в виду то, что в последний день отношения между животными и людьми примут новую форму и что сам человек примирится со своей животной природой» (Агамбен, 2012, стр. 9-11). Для того, чтобы наша природа (животность) средствами технологий не была усилена и обращена против нас, нам следует быть более внимательными к собственным ограничениям и слабостям. В стремительно меняющихся условиях они могут стать новой силой. Мы должны перейти от парадигмы контроля к парадигме заботы в наших цифровых средах. Цифровое взаимодействие во многом обусловлено бихевиориальными принципами, которые в дизайне интерфейс-оболочек оказались соотнесены с критериями эффективности, скорости и продуктивности как «технологическими добродетелями». Однако в условиях совершенствования технологий эти критерии все больше показывают свою ограниченность, поскольку скорее подавляют, чем раскрывают человека. Наоборот, ограничения человеческой природы, контрпродуктивные ее проявления - становятся все более привлекающим внимание феноменом, поскольку позволяют выделить специфику человеческого существа в мире разумных машин. Открытость интерфейса может обернуться падением в вихревые потоки принуждением 
к действию, истощением, обессмысливанием, а потому парадоксальным образом потоковому переживанию, мотивации к действию, вознаграждению за выбранный порядок действий как ключевым моментам бихевиориальной матрицы, должны быть найдены контртенденции в виде замедления, или даже скуки, заострения внимания, возвращению к себе, в собственное время и место, в собственное тело. Меньше значит больше. Такой парадокс следует принять в учет для понимания экзистенциального дизайна цифровых оболочек: цифра должна не только увлекать вовне, но и давать возможность вернуться, обратиться к себе, традиционно табуированные в цифровом дизайне моменты - замедления, скука, боль - существенны и должны быть допущены для возвращения экзистенциальной чуткости, в конечном счете для возвращения к собственному телу, которое и будет означать примирение человека с собственной животностью (сейчас речь идет скорее о наступлении на нее). Иными словами, цифровой дизайн может способствовать не тому, что нечто будет сделано субъектом действия, но тому, что нечто измениться в самом субъекте действия, причем он будет открыт принципам и причинам этого изменения. Вызванная технологиями борьба за выживание в условиях растущих скоростей, многообразной сложности взаимодействия и фрагментарности событий, средствами самих же технологий (при соблюдении условий экзистенциального, а не бихевиориального проектирования) может быть обращена в более тонкую, прочувствованную и осознанную жизнь.

\section{БЛАГОДАРНОСТИ}

Работа выполнена при финансовой поддержке гранта Президента Российской Федерации. Проект МК-169.2021.2. СПбГУ

\section{Список литературы}

Boothroyd, D. (2009). Touch, time and technics: Levinas and the ethics of haptic communications. Theory, Culture and Society, 26(2-3), 330-335. doi: 10.1177/0263276409103123

Bush, V. (1991). As We May Think. The Atlantic Monthly. In J. Nyce \& P. Kahn (Eds.), «As We May Think». From Memex to Hypertext: Vannevar Bush and the Mind's Machine (pp. 85-112). London: Academic Press.

Détienne, M., \& Vernant, J. P. (1974). Les ruses de l'intelligence [The wiles of intelligence]. Paris: La métis des Grecs. Flammarion (In French).

Elo, M. (2012). Digital finger: Beyond phenomenological figures of touch. Journal of Aesthetics \& Culture, 4(1), 1-12. doi: 10.3402/jac.v4i0.11511 
Fogg, B. J. (2002). Persuasive Technology: Using Computers to Change What We Think and Do. Burlington, Massachusetts: Morgan Kaufmann.

Hallnaes, L., \& Redstroem, J. (2001). Slow Technology: Designing for Reflection. Personal Ubiquitous Computing, 5(3), 201-212. doi: 10.1007/PL00000019

Husserl, E. (1952). Ideen zu einer reinen Phaenomenologie und Phaenomenologische Philosophie. Zweites Buch: Phaenomenologische Untersuchungen zur Konstitution. Haag: Martinus Nijhoff.

Landes, D. A. (2007). Le Toucher» and the «Corpus» of Tact: Exploring Touch and Technicity with Jacques Derrida and Jean-Luc Nancy. Contact!: The Art of Touch / L'Art Du Toucher, 47(3), 85-92. doi: 10.1353/esp.2007.0052

Sengers, P., Boehner, K., David, S., \& Kaye, J. (2005). Reflective Design». In O. W. Bertelsen, N. O. Bouvin, P. G. Krogh., \& K. Morten (Eds.), Proceedings of the 4th Decennial Conference on Critical Computing: Between Sense and Sensibility (pp. 4958). Aarhus, Denmark: ACM.

Августин, Бл. (1998). О граде Божьем. В Творения в 4-х mm (Т. 3). Санкт-Петербург; Киев: Алетейя. УЦИММ-пресс.

Агамбен, Дж. (2012). Открытое. Москва: РГГУ.

Агамбен, Дж. (2019). Царство и Слава. К теологической генеалогии экономики и управления. Москва; Санкт-Петербург: Издательство Института Гайдара, Факультет свободных наук и искусств СПбГУ.

Арендт, Х. (2017). Vita Activa, или O деятельной жсизни. Москва: Ад Маргинем Пресс.

Барт, Р. (1994). Литература и значение. В Р. Барт, Избранные работы: Семиотика, Поэтика (сс. 276-296). Москва: Издательская группа «Прогресс», «Универс».

Беньямин, В. (2002). Происхождение немеикой барочной драмыл. Москва: Аграф.

Беньямин, В. (2012). Капитализм как религия. В И. Чубаров \& И. Б. В. Беньямин (Ред.), Медиаэстетические произведения. Сборник статей (сс. 99-107). Москва: РГГУ.

Брюкнер, П. (2011). Вечная эйфория: Эссе о принудительном счастье. Санкт-Петербург: Издательство Ивана Лимбаха.

Вахштайн, В. (2017). Пересборка повседневности: Беспилотники, лифты и проект ПКМ-1. Логос, 117(2), 2-48. doi: 10.22394/0869-5377-2017-2-1-44

Гебауэр, Г. (2013). Тело, созданное аппаратом, и аппарат, создающий тело. Логос, 95(5), 97-107.

Деррида, Ж. (2006). Geschlecht II: Рука Хайдеггера. В М. Хайдеггер, Что зовется мышиением? (сс. 263-315). Москва: Издательский дом «Территория будущего».

Канторович, Г. (2013). Два тела короля. Москва: Издательство Института Гайдара.

Киттлер, Ф. (2009). Оптические медиа: Берлинские лекции 1999 г. Москва: Логос; Гнозис.

Латур, Б. (2006). Где недостающая масса? Социология одной двери. В В. С. Вахштайн (Ред.), Социология вещей. Москва: Издательский дом «Территория будущего». 
Ленкевич, А. С. (2019). На пути к медиаэстезису: Производство присутствия в компьютерных играх. Международный журнал исследований культуры, 34(1), 20-33. doi: 10.24411/2079-1100-2019-00002

Манко, Дж. (2019). Как заселялась Европа. От первых людей до викингов. Москва: Языки славянских культур.

Манович, Л. (2017). Теории софт-культуры. Нижний Новгород: Красная ласточка.

Мерло-Понти, М. (1999). Феноменология восприятия. Санкт-Петербург: Ювента, Наука.

Николаева, Ж. В. (2016). Slow life. Новая философия неспешности. Обсерватория культуры, 1(1), 24-30. doi: 10.25281/2072-3156-2016-1-1-24-30

Поланьи, К. (2014). Великая трансформаџия: Политические и экономические истоки нашего времени. Санкт-Петербург: Алетейя.

Пшера, А. (2017). Интернет животных: Новый диалог между человеком и природой. Москва: Ад Маргинем.

Флюссер, В. (2016а). Не-Вещь II. В В. Флюссер, О положении вещей. Малая философия дизайна (сс. 118-123). Москва: Ад Маргинем Пресс.

Флюссер, В. (2016b). Существует ли этика промышленного дизайна? В В. Флюссер, $O$ положении вещей. Малая философия дизайна (сс. 75-79). Москва: Ад Маргинем Пресс.

Фрейд, 3. (1995). О добывании огня. В 3. Фрейд, Художник и фантазирование (сборник работ) (сс. 339-342). Москва: Республика.

Хайдеггер, М. (2006). Что зовется мышилением? Москва: Издательский дом «Территория будущего».

Харрари, Ю. Н. (2020). Ното Deus. Краткая история будущего. Москва: Издательство Синдбад.

Шваб, К. (2018). Технологии четвёртой промышиенной революиии. Москва: Эксмо.

Якобсон, Р. (1975). Лингвистика и поэтика. В М. Я. Поляков (Ред.), Структурализм: «за» $u$ «против». Сборник статей (сс. 193-230). Москва: Издательство «Прогресс».

Ямпольский, М. (2019). Изображение. Курс лекций. Москва: Новое литературное обозрение.

\section{References}

Agamben, J. (2012). The Open. Moscow: Russian State University for the Humanities. (In Russian).

Agamben, J. (2019). The Kingdom and the Glory: For a Theological Genealogy of Economy and Government. Moscow, St. Petersburg, Russia: Publishing House of the Institute of Gaidar, Faculty of Liberal Sciences and Arts, St. Petersburg State University. (In Russian). 
Arendt, H. (2017). Vita Activa, or On the Active Life. Moscow: Ad Marginem Press. (In Russian).

Augustine, the Blessed. (1998). About the City of God. In Works in 4 volumes (Vol. 3). St. Petersburg; Kiev: Aletheia. UCIMM Press. (In Russian).

Barth, R. (1994). Literature and meaning. In R. Barth, Selected works: Semiotics, Poetics (pp. 276-296). Moscow: Progress Publishing Group, Univers. (In Russian).

Benjamin, W. (2002). The Origin of German Tragic Drama. Moscow: Agraf Publ. (In Russian).

Benjamin, W. (2012). Capitalism as a religion. In I. Chubarov \& I. Boldyrev (Eds.), The doctrine of similarity. Media aesthetic works. Selected articles (pp. 99-107). Moscow: Russian State University for the Humanities. (In Russian).

Boothroyd, D. (2009). Touch, time and technics: Levinas and the ethics of haptic communications. Theory, Culture and Society, 26(2-3), 330-335. doi: $10.1177 / 0263276409103123$

Brueckner, P. (2011). Perpetual Euphoria: On the Duty to Be Happy. St. Petersburg: Ivan Limbakh Publishing House. (In Russian).

Bush, V. (1991). As We May Think. The Atlantic Monthly. In J. Nyce \& P. Kahn (Eds.), «As We May Think». From Memex to Hypertext: Vannevar Bush and the Mind's Machine (pp. 85-112). London: Academic Press.

Derrida, J. (2006). Geschlecht II: Heidegger's Hand. In M. Heidegger, What is Thinking? (pp. 263-315). Moscow: Publishing House «Territory of the Future».

Détienne, M., \& Vernant, J. P. (1974). Les ruses de l'intelligence [The wiles of intelligence]. Paris: La métis des Grecs. Flammarion (In French).

Elo, M. (2012). Digital finger: Beyond phenomenological figures of touch. Journal of Aesthetics \& Culture, 4(1), 1-12. doi: 10.3402/jac.v4i0.11511

Flusser, V. (2016b). Is there an ethics of industrial design? In V. Flusser, On the state of affairs. Small design philosophy (pp. 75-79). Moscow: Ad Marginem Press. (In Russian).

Flusser, V. (2016a). Non-Thing II. In V. Flusser, On the state of affairs. Small design philosophy (pp. 118-123). Moscow: Ad Marginem Press. (In Russian).

Fogg, B. J. (2002). Persuasive Technology: Using Computers to Change What We Think and Do. Burlington, Massachusetts: Morgan Kaufmann.

Freud, Z. (1995). On making fire. In Z. Freud, Artist and Phantasy (collection of works) (pp. 339-342). Moscow: Republic. (In Russian).

Gebauer, G. (2013). The Body Made by Machines, and Body-Making Machine. Logos, 95(5), 97-107. (In Russian).

Hallnaes, L., \& Redstroem, J. (2001). Slow Technology: Designing for Reflection. Personal Ubiquitous Computing, 5(3), 201-212. doi: 10.1007/PL00000019

Harrari, Y. N. (2020). Homo Deus. A brief history of the future. Moscow: Publishing House Sinbad. (In Russian). 
Heidegger, M. (2006). What is Thinking? Moscow: Publishing House "Territory of the Future". (In Russian).

Husserl, E. (1952). Ideen zu einer reinen Phaenomenologie und Phaenomenologische Philosophie. Zweites Buch: Phaenomenologische Untersuchungen zur Konstitution. Haag: Martinus Nijhoff.

Jacobson, R. (1975). Linguistics and Poetics. In M. Ya. Polyakov (Ed.), Structuralism: pros and cons. Collection of articles (pp. 193-230). Moscow: Progress Publishing house. (In Russian).

Kantorovich, G. (2013). The King's Two Bodies: A Study in Medieval Political Theology. Moscow: Gaidar Institute Publishing House. (In Russian).

Kittler, F. (2009). Optical Media: Berlin Lectures 1999. Moscow: Logos Publ.; Gnosis Publ. (In Russian).

Landes, D. A. (2007). Le Toucher» and the «Corpus» of Tact: Exploring Touch and Technicity with Jacques Derrida and Jean-Luc Nancy. Contact!: The Art of Touch / L'Art Du Toucher, 47(3), 85-92. doi: 10.1353/esp.2007.0052

Latour, B. (2006). Where are the missing masses? The sociology of a few mundane artifacts. In V. S. Vakhshtein (Ed.), Sociology of things. Moscow: Publ. House "Territory of the Future". (In Russian).

Lenkevich, A. S. (2019). On the Way to Media Esthesis: Production of Presence in Computer Games. International Journal of Cultural Research, 34(1), 20-33. doi: 10.24411/2079-1100-2019-00002 (In Russian).

Manco, J. (2019). Ancestral Journeys: The Peopling of Europe from the First Venturers to the Vikings. Moscow: Languages of Slavic Cultures Publ. (In Russian).

Manovich, L. (2017). Theories of Soft Culture. Nizhny Novgorod: Red Swallow. (In Russian).

Merleau-Ponty, M. (1999). Phenomenology of Perception. St. Petersburg: Juventa, Science Publ. (In Russian).

Nikolaeva, Zh. V. (2016). Slow life. A New Philosophy of Slowness. Observatory of culture, 1(1), 24-30. doi: 10.25281/2072-3156-2016-1-1-24-30 (In Russian).

Polanyi, K. (2014). The Great Transformation: The Political and Economic Origins of Our Time. St. Petersburg: Aletheia. (In Russian).

Pshera, A. (2017). Internet of Animals: a new dialogue between humans and nature. Moscow: Ad Marginem Press. (In Russian).

Schwab, K. (2018). Shaping The Fourth Industrial Revolution. Moscow: Eksmo Publ. (In Russian).

Sengers, P., Boehner, K., David, S., \& Kaye, J. (2005). Reflective Design». In O. W. Bertelsen, N. O. Bouvin, P. G. Krogh., \& K. Morten (Eds.), Proceedings of the 4th Decennial Conference on Critical Computing: Between Sense and Sensibility (pp. 4958). Aarhus, Denmark: ACM.

Vakhstein, V. (2017). Reassembly of Daily Life: drones, elevators and the PKM-1 project. Logos, 117(2), 2-48. doi: 10.22394/0869-5377-2017-2-1-44 (In Russian).

Yampolsky, M. (2019). Image. Lectures. Moscow: New Literary Review. (In Russian). 